Original Research Paper

\title{
Abundance and Diversity of Diatom Class Bacillariophyceae in the Waters of Tanjung Luar Fish Landing Based
}

\author{
Niswatul Audah ${ }^{1}$, Lalu Japa ${ }^{*}$, dan M. Yamin ${ }^{1}$ \\ ${ }^{1}$ Biology Education Study Program, Faculty of Teacher Training and Education, University of \\ Mataram
}

\author{
Article History \\ Received : May 05 ${ }^{\text {th }}, 2021$ \\ Revised : May 20 ${ }^{\text {th }}, 2021$ \\ Accepted : June 10 ${ }^{\text {th }}, 2021$ \\ Published : June $18^{\text {th }}, 2021$ \\ *Corresponding Author: \\ Lalu Japa, \\ Biology Education Study \\ Program, Faculty of Teacher \\ Training and Education, \\ University of Mataram; \\ Email: 1japa@unram.ac.id
}

\begin{abstract}
Diatom class Bacillariophyceae are world wide distribution and commonly dominated the phytoplankton community. The community of diatom class Bacillariophyceae of the waters Tanjung Luar Fish Landing Based (FLB) has never been reported. This study aims to determine the abundance and diversity of diatom class Bacillariophyceae. The sampling sites were determined by using a systematic random sampling method. Data of diatom class Bacillariophyceae were analyzed for species abundance, species diversity index and species dominance index calculations. The results showed, that the abundance of diatom class Bacillariophyceae species were 322.000 ind/L (low category), the species diversity index of diatom class Bacillariophyceae was 2.162 (moderate category), and the species dominance index was 0.138 (none of species dominance).
\end{abstract}

Keywords: Abundance; Diversity; Diatom; Bacillariophyceae;

Tanjung Luar; Fish Landing Based.

\section{Pendahuluan}

Tanjung Luar merupakan kawasan pesisir yang sebagian besar masyarakatnya bermata pencaharian sebagai nelayan. Hampir setiap hari aktivitas nelayan, seperti pendaratan dan pemasaran berbagai hasil tangkapan laut dan pelelangan berbagai spesies hiu berlangsung di kawasan tersebut (Fahmi \& Dharmadi 2015; Sentosa dan Dharmadi 2017). Aktivitas-aktivitas yang berlangsung menjadikan kawasan Tanjung Luar ditetapkan sebagai Pangkalan Pendaratan Ikan (PPI) Tanjung Luar (KKP, 2016).

Penetapannya sebagai PPI memberikan dampak positif dalam mengoptimalkan sumber daya pesisir dan laut. Namun, berdampak negatif, limbah-limbah yang dihasilkan dapat menjadi sumber pencemaran bagi lingkungan. Jika limbah tersebut masuk ke perairan secara terus-menerus mengakibatkan kualitas lingkungan akan mengalami penurunan. Hal ini pada akhirnya akan berpengaruh secara langsung maupun tidak langsung terhadap biota air, kesehatan masyarakat sekitarnya, dan tentu saja kesehatan lingkungan PPI sendiri
(Siburian et al., 2017; Wahyudi et al., 2017). Perubahan kualitas perairan mempengaruhi organisme yang hidup didalamnya seperti fitoplankton. Fitoplankton merupakan organisme mikroskopis yang hidup melayang di perairan yang memegang peran penting dalam menentukan produktivitas suatu perairan karena pada tingkat tropik berperan sebagai produsen bagi berlangsungnya proses kehidupan (transfer energi melalui rantai makanan) (Sulistiowati et al., 2016). Keberadaan fitoplankton, terutama diatom kelas Bacillariophyceae yang umumnya mendominasi perairan laut (Nurbaeti dan Octarina, 2012; Wulandari et al., 2014), juga dapat dipengaruhi keberdaannya sebagai akibat dari perubahan kualitas air habitatnya.. Penelitian terkait fitoplankton yaitu didominasi oleh Bacillariophyceae antara lain: Yuliana et al., (2012), Imran (2016), Faturohman et al., (2016), dan Nasution et al., (2019).

Informasi mengenai kelimpahan dan keanekaragaman spesies diatom kelas Bacillariophyceae di perairan Pangkalan Pendaratan Ikan Tanjung Luar sampai saat ini 
Audah, N. et al. (2021). Jurnal Biologi Tropis, 21 (2): 448 - 455

DOI: http://dx.doi.org/10.29303/jbt.v21i2.2699

belum pernah ada laporannya. Untuk itu, perlu dilakukan penelitian tentang "Kelimpahan dan Keanekaragaman Bacillariophyceae di Perairan Pangkalan Pendaratan Ikan Tanjung Luar".

\section{Bahan dan Metode}

Sampel air laut diambil di perairan PPI Tanjung Luar pada 17 Juni 2020. Pengambilan sampel air laut dilakukan di 5 (lima) titik (Gambar 1). Sampel air laut di setiap titik diperoleh sebanyak $50 \mathrm{ml}$ dari pemekatan $100 \mathrm{~L}$ air laut menggunakan jaring plankton berukuran mata jaring $20 \mu \mathrm{m}$. Setiap sampel diawet dengan formalin konsentrasi 4\%. Pengamatan dan identifikasi spesies diatom kelas Bacillariophyceae dilakukan di Laboratorium Biologi FKIP Universitas Mataram. Sampel diamati di bawah mikroskop mulai dari perbesaran 10x10, 10x20, dan atau 10x40 (400 kali). Pengamatan setiap sampel dilakukan sebanyak 3 kali ulangan. Fitoplankton yang diperoleh diidentifikasi spesiesnya berdasarkan ciri yang tampak (morfologi) dengan mengacu pada buku identifikasi dari Bold dan Whynne (1985), Botes (2003), Wehr dan Sheath (2003), Kandari et al., (2009), Patten et al., (2010), dan Bellinger dan Sigee (2015). Data diatom kelas Bacillariophyceae meliputi kelimpahan setiap spesies diolah menggunakan rumus Romimohtarto dan Juwana (2007). Indeks keanekaragaman spesies "Indeks ShannonWiener $\left(\mathrm{H}^{\prime}\right)$ menggunakan rumus dari Bellinger dan Sigee (2015). Indeks dominansi spesies "Indeks Dominansi Simpson" dari rumus Bellinger dan Sigee (2015).

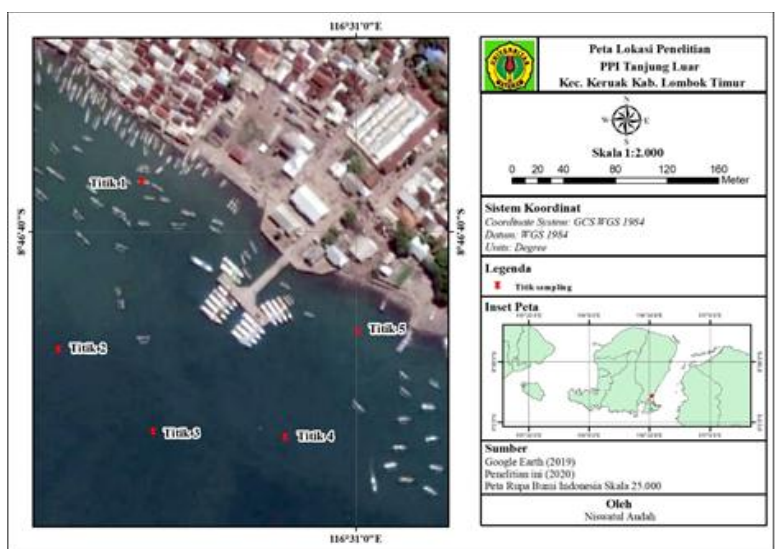

Gambar 1. Posisi Titik Sampling Di Perairan PPI Tanjung 


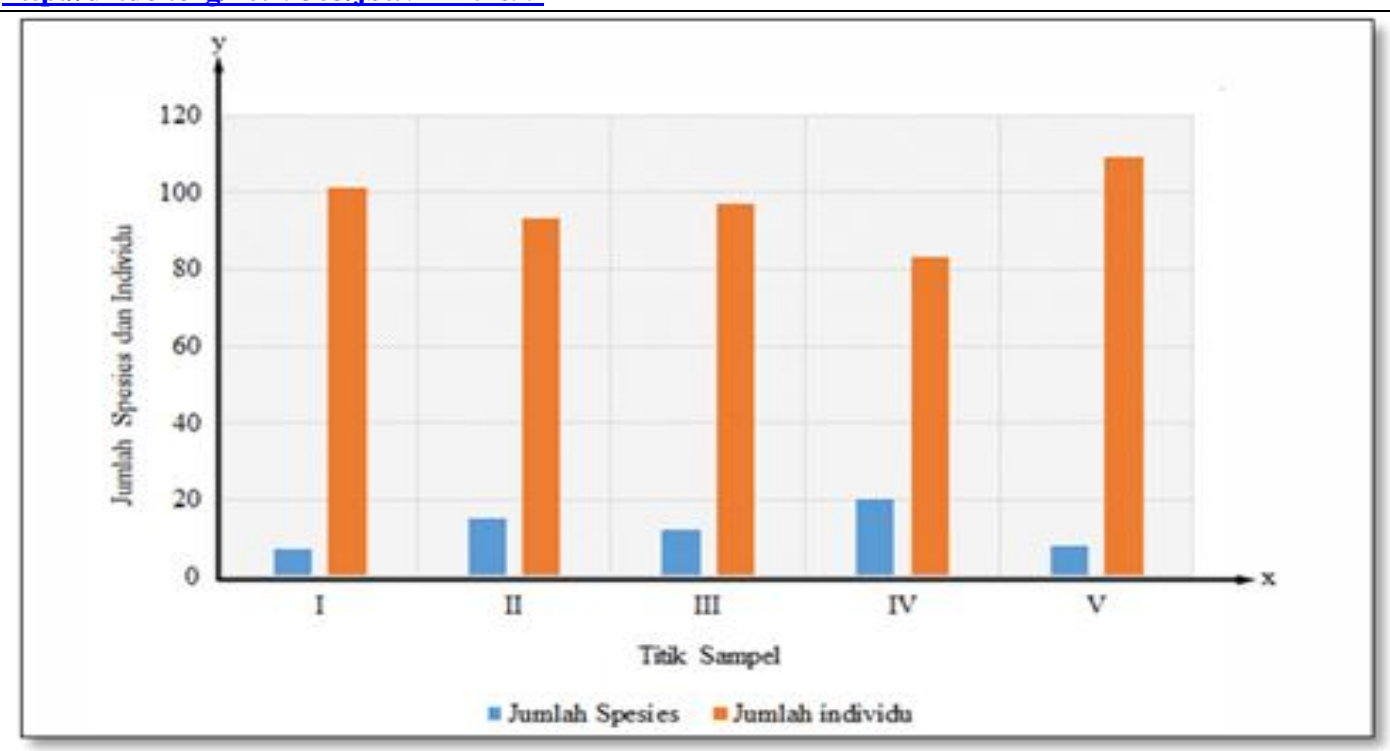

Gambar 2. Perbandingan Jumlah Taksa pada Setiap Titik Sampel di Perairan PPI Tanjung Luar

Kelimpahan rata-rata spesies Bacillariophyceae di perairan PPI Tanjung Luar sebesar 322,000 ind/L. Perbandingan kelimpahan Bacillariophyceae pada masing masing titik pengambilan sampel disajikan pada Gambar 3. Berdasarkan kriteria Raymont 1963 (dalam Linus et al., 2016), jika kelimpahan kurang dari 2000 ind/L maka kelimpahan spesies tersebut tergolong rendah. Kelimpahan spesies ini lebih rendah dibandingkan kelimpahan spesies Bacillariophyceae di Pantai Jeranjang Lombok Barat yang dilaporkan Nurlaelatun et al., (2018) yaitu 786,94 ind/L dan di Pantai Desa Madayin Lombok Timur yakni 3.191,333 ind/L (Armiani dan Harisanti, 2018). Spesies Bacillariophyceae yang paling tinggi kelimpahannya berturut-turut adalah Chaetoceros affinis 42,667 ind/L.

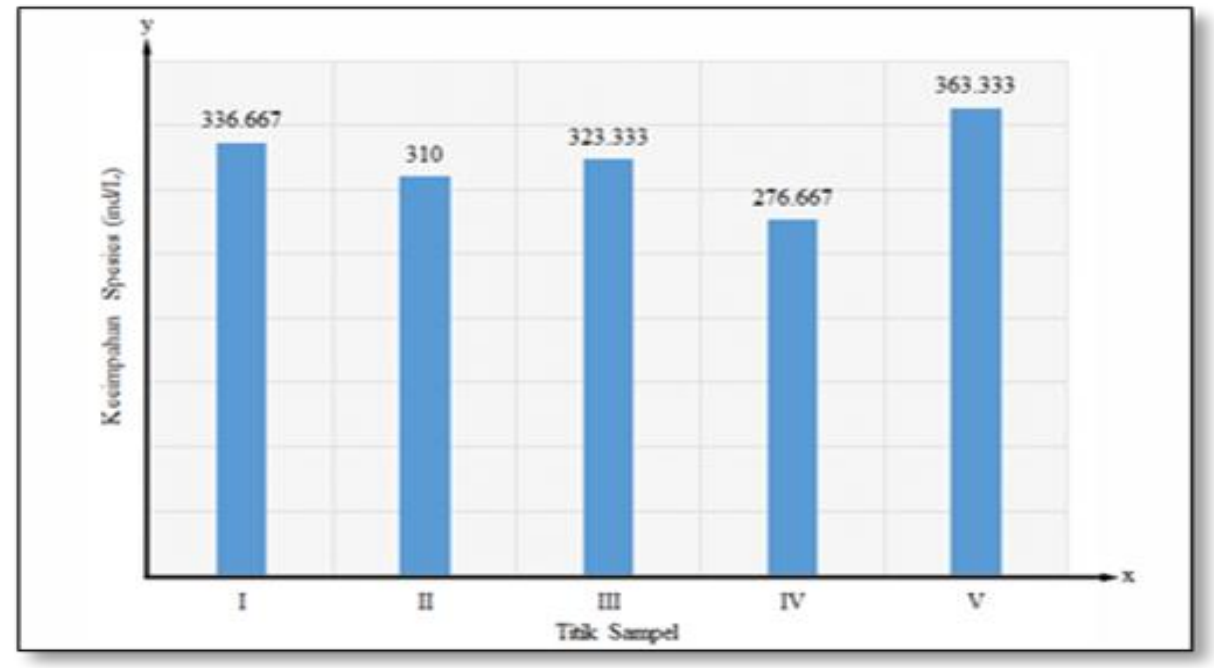

Gambar 3. Perbandingan Nilai Kelimpahan Spesies (N) Bacillariophyceae Setiap Titik Sampel di Perairan PPI Tanjung Luar

Kelimpahan Chaetoceros affinis ini lebih rendah dibandingkan dengan kelimpahan yang ditemukan di perairan Selat Bali yakni 7994
ind/L (Khasanah et al., 2013) dan di perairan pantai Jawa Tengah 2542 ind/L (Hidayat, 2018), namun lebih tinggi dari Sulistiowati et al., (2016) 
Audah, N. et al. (2021). Jurnal Biologi Tropis, 21 (2): 448 - 455

DOI: http://dx.doi.org/10.29303/jbt.v21i2.2699

di perairan pantai Jayapura pada musim kemarau yakni 0,6 ind/L. Menurut Persada et al., (2019), Chaetoceros affinis adalah salah satu spesies dari genus Chaetoceros kelompok diatom dari bangsa Centrales terbanyak dibandingkan bangsa Penales yang ditemukan di perairan tawar maupun laut. Hal ini diperkuat oleh Hartanto (2020). Tingginya kelimpahan genus ini disebabkan karena mempunyai bentuk dan ukuran yang unik, dengan bentuk seperti rantai atau kumpulan sel dan memiliki chaeta sehingga kurang disukai oleh pemangsa herbivora serta memiliki kemampuan adaptasi lebih baik dibandingkan genus lainnya (Bakhtiar dan Ta'alidin, 2013; Wulandari et al., 2014).

Kelimpahan spesies tertinggi pada titik sampel V yaitu 363,333 ind/L, sedangkan kelimpahan terendah ditemukan pada titik sampel IV sebesar 276,667 ind/ (Gambar 3). Tingginya kelimpahan Bacillariophyceae pada titik sampel V, dapat diduga karena letaknya yang lebih dekat dengan daratan. Hal yang serupa terjadi di perairan selat Alas (Radiarta, 2013) dan di pantai Timur Surabaya yang (Putri dan Sari, 2015). Lokasi yang berada di dekat daratan menyediakan nutrisi lebih besar karena mendapatkan pasokan zat hara dari daratan yang mendukung pertumbuhan Bacillariophyceae.

Rendahnya kelimpahan spesies Bacillariophyceae pada titik sampel IV karena lokasi lebih jauh dari daratan sehingga diduga sedikit mendapat pasokan zat hara untuk

pertumbuhan Bacillariophyceae. Hal tersebut juga yang ditemukan Bakhtiar dan Ta'alidin (2013). Pernyataan ini perkuat oleh penelitian Ariana et al., (2014) dan Purnamaningtyas et al. (2019).

\section{Indeks Keanekaragaman Spesies}

Indeks keanekaragaman spesies Bacillariophyceae antar titik sampel berkisar 1,858 - 2,599. Kisaran indeks keanekaragaman spesies ini lebih tinggi dibandingkan kisaran indeks keanekaragaman 1,25 - 1,37 di pantai Jeranjang Lombok Barat (Nurlaelatun et al., 2018) dan indeks keanekaragaman 0,005-0,102 di perairan Intertidal Kota Kupang yang dilaporkan oleh Haninuna et al., (2015). Ratarata indeks keanekaragaman spesies di perairan PPI Tanjung Luar yaitu 2,141 yakni berdasarkan Wardhana (2006) tergolong sedang. Indeks keanekaragaman spesies tertinggi terjadi pada titik IV sebesar 2,599 dan terendah terdapat pada titik V sebesar 1,858 (Gambar 4).

Hal tersebut menunjukkan bahwa nutrisi tidak banyak mempengaruhi indeks keanekaragaman. Hal serupa dilaporkan oleh Putri dan Sari (2015), bahwa analisis korelasi menunjukkan zat hara memberikan pengaruh yang lemah terhadap indeks diversitas dan diperkuat oleh penelitian Soedibjo (2007), tidak ditemukannya korelasi antara indeks diversitas dan zat hara.

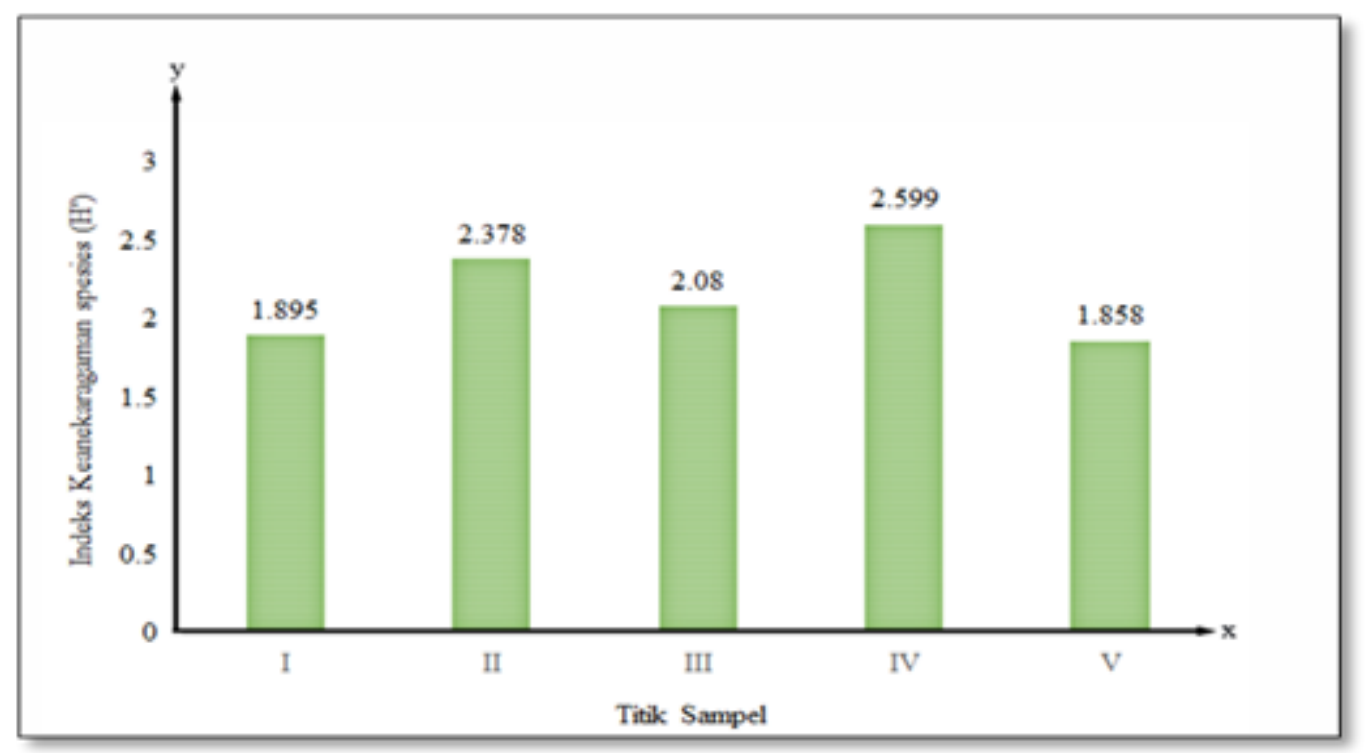

Gambar 4. Perbandingan Indeks Keanekaragaman Spesies (H’) Bacillariophyceae Setiap 
Indeks Dominasi Spesies

Indeks dominansi spesies Bacillariophyceae di perairan PPI Tanjung Luar dapat dilihat pada (Gambar 5), bahwa titik sampel V dijumpai tingkat dominansi spesies tertinggi yakni 0,171 , sedangkan terendah ditemukan pada titik sampel IV yakni 0,097. Indeks dominansi rata-rata perairan PPI Tanjung Luar sebesar 0,137 lebih rendah dibanding indeks dominansi spesies Bacillariophyceae 0,239 di perairan Pantai Desa Madayin Lombok Timur yang dilaporkan Armiani dan Harisanti (2018). Indeks dominansi tersebut menandakan bahwa tidak ada spesies Bacillariophyceae yang mendominasi perairan PPI Tanjung Luar (Odum, 1993 dalam Purnamaningtyas et al., 2019). Hal serupa yang dilaporkan oleh Wiyarsih et al., (2019).

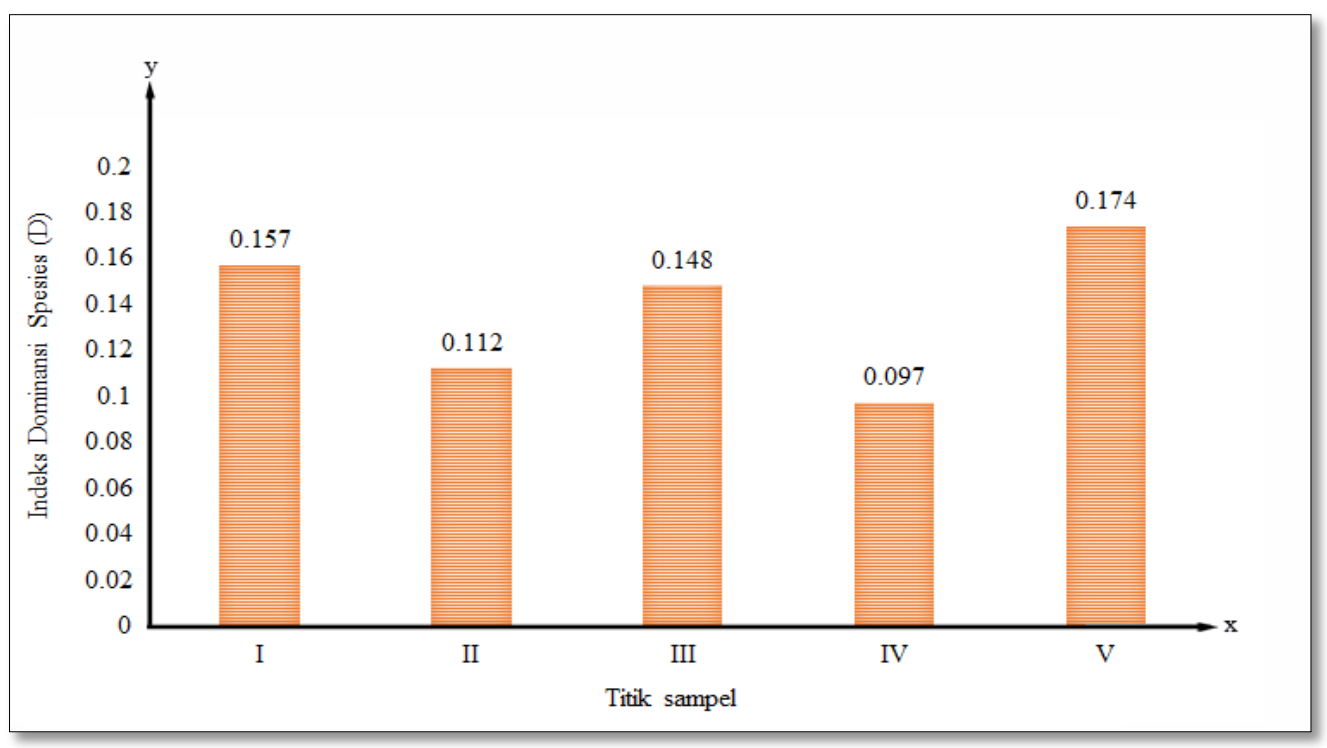

Gambar 5. Perbandingan Indeks Dominansi Spesies (D) Bacillariophyceae Setiap Titik Sampel di Perairan PPI Tanjung Luar

Tidak adanya spesies dari Bacillariphyceae yang mendominasi perairan ini yang menunjukkan tidak adanya kompetisi antara satu spesies dengan spesies diatom lainnya karena spesies dari kelas diatom memiliki kemampuan beradaptasi dengan baik walaupun pada lingkungan yang ekstrim (Radiarta et al., 2015). Menurut Usman et al., (2013) bahwa suatu ekosistem dengan keanekaragaman tinggi atau sedang maka dominansinya rendah.

\section{Kesimpulan}

Berdasarkan hasil penelitian dapat disimpulkan bahwa: (1) Kelimpahan spesies diatom kelas Bacillariophyceae di perairan Pangkalan Pendaratan Ikan Tanjung Luar secara keseluruhan 322,000 ind/L yaitu tergolong rendah. (2) Indeks keanekaragaman spesies Bacillariophyceae di perairan Pangkalan Pendaratan Ikan Tanjung Luar sebesar 2,162 yaitu tergolong sedang. (3) Indeks dominansi spesies di perairan Pangkalan Pendaratan Ikan Tanjung Luar sebesar 0,138 yaitu tergolong rendah (tidak ada yang mendominasi).

\section{Ucapan terima kasih}

Terima kasih kepada semua pihak yang telah membantu baik moril maupun materil sehingga terselesaikannya penelitian ini.

\section{Referensi}

Aini, Y. Q., A. A. Idrus., \& L. Japa. (2018). Komunitas Plankton pada Perairan Habitat Mangrove di Gili Sulat Lombok Timur. Prosiding Seminar Nasional Pendidikan Biologi, 32-40.

Ariana, D., J. Samiaji., \& S. Nasution (2014). Komposisi Jenis dan Kelimpahan Perairan 
Laut Riau. Jurnal Online Mahasiswa Fakultas Perikanan dan Ilmu Kelautan Universitas Riau, 1(1): 1-5.

Armiani, S., \& B. M. Harisanti (2018). Kualitas Air Laut Ditinjau Indeks Keanekaragaman Fitoplankton di Perairan Pantai Desa Madayin Lombok Timur. Jurnal Ilmiah Biologi, 6(2): 1-6.

Bakhtiar, D., \& Z. Ta'alidin (2013). Kelimpahan dan Kandungan Klorofil-A Fitoplankton di Perairan Pulau Enggano. Mitra Bahari, 7(1): 28-39.

Bellinger, E. G., \& D. C. Sigee (2015). Freshwater Algae Identification, Enumeration, and Use As Bioindicators. India: Willey Backwell.

Bold, H. C., \& M. J. Whynne (1985). Introduction to the Algae Structure and Reproduction. United States of America: Pretice-Hall Inc.

Botes, L. (2003). Phytoplankton Identification Catalogue - Saldanha Bay, South Africa. London: GloBallast Monograph.

Fahmi \& Dharmadi (2015). Pelagic Shark Fisheries of Indonesia's Eastern Indian Ocean Fisheries Management Region. African Journal of Marine Science, 37(2): 259-265.

Faturohman, I., Sunarto, \& Nurruhwati, I. (2016). Korelasi Kelimpahan Plankton dengan Suhu Perairan Laut di Sekitar PLTU Cirebon. Jurnal Perikanan Kelautan, 4(1): 115-122.

Haninuna, E. D. N., R. Gimin., \& L. M. R. Kaho. (2015). Pemanfaatan Fitoplankton sebagai Bioindikator Berbagai Jenis Polutan di Perairan Intertidal Kota Kupang. Jurnal Ilmu Lingkungan, 13(2): 72-85.

Hartanto, A. T. (2020). Plankton Indexes and Heavy Metal Pollution in Kendal Coastal Waters, Indonesia. Aquculture, Aquarium, Conservation dan Legislation, 13(1): 46-
63.

Hidayat, J. W. (2018). The Water Quality and Cultivant Enrichment Potency of Pond Based on Saprobic Index at North Coastal Waters of Central Java, Indonesia. Journal of Physics, 1025(1): 1-8.

Imran, A. (2016). Struktur Komunitas Plankton sebagai Bioindikator Pencemaran di Perairan Pantai Jeranjang Lombok Barat. JIME, 2(1): 1-8.

Japa, L., Suripto, \& I. G. Mertha (2013). Hubungan Kualitatif Fitoplankton dan Zooplankton Perairan Suaka Perikanan Gili Ranggo Teluk Serewe Lombok Timur. Jurnal Biologi Tropis, 13(1): 4554.

Kandari, M. A., F. A. Yamani., \& K. A. Rifaie. (2009). Marine Phytoplankton Atlas of Kuwait's Waters. Kuwait: Kuwait Institute for Scientific Research.

Kementerian Kelautan dan Perikanan Republik Indonesia (2016). Keputusan Menteri Kelautan dan Perikanan Republik Indonesia Nomor 33/KEPMEN-KP/2016 tentang Penetapan Pelabuhan Perikanan Tanjung Luar Sebagai Pangkalan Pendaratan Ikan Tanjung Luar, di Provinsi Nusa Tenggara Barat. Jakarta: KKP.

Khasanah, R. I., A. Sartimbul., \& E. Y. Herawati. (2013). Kelimpahan dan Keanekaragaman Plankton di Perairan Selat Bali. Ilmu Kelautan, 18(4): 193-202.

Linus, Y., Salwiyah, \& N. Irawati (2017). Status Kesuburan Perairan Berdasarkan Kandungan klorofil- $\alpha$ di Perairan Bungkutoko Kota Kendari. Jurnal Manajemen Sumber Daya Perairan, 2(1): 101-111.

Nasution, A., N. Widyorini., \& F. Purwanti. (2019). Analisis Hubungan Kelimpahan Fitoplankton dengan Kandungan Nitrat dan Fosfat di Perairan Morosari, Demak. 
Journal of Maquares, 8(2): 78-86.

Nurbaeti, N., \& P. Octorina (2012). Hubungan Keanekaragaman Fitoplankton dengan Kualitas Air di Situ Minera Bekas Galian Gekbrong, Cianjur-Jawa Barat. Jurnal Pertanian-UMMI, 1(2): 3-9.

Nurlaelatun, H., L. Japa., \& D. Santoso (2018). Keanekaragaman dan Kelimpahan Diatom (Bacillariophyceae) di Pantai Jeranjang Desa Taman Ayu Kecamatan Gerung Kabupaten Lombok Barat. Jurnal Biologi Tropis, 18(1): 13-20.

Patten, V. P., J. Y. Li., \& G. H. Wikfors (2010). A Student's Guide to Common Phytoplankton of Long Island Sound. Florida: Connecticut Sea Grant College Program 2012.

Persada, A.Y., Z. I. Navia., A. Saputri., K. A. Putri., \& B. A. Fajar. (2019). Inventaris Jenis Fitoplankton di Pulau Pusong, Langsa, Aceh. Journal of Islamic Science and Technology, 5(1): 67-75.

Purnamaningtyas, S. E., Mujiyanto, \& Riswanto. (2019). Distribusi dan Kelimpahan Fitoplankton di Teluk Gerupuk, Nusa Tenggara Barat. Jurnal Akuatika Indonesia, 4(1): 24-30.

Purnomo, A. A., I. K. Junitha., \& N. M. Suartini. (2015). Variasi Spesies Diatom pada Tipe Perairan Berbeda untuk Kepentingan Forensik sebagai Petunjuk Kematian Akibat Tenggelam. Jurnal Simbiosis, 3(1): 247-257.

Putri, S. I. P., \& S. H. J. Sari. (2015). Struktur Komunitas Fitoplankton dan Kaitannya dengan Ketresediaan Zat Hara dan Parameter Kualitas Air lainnya di Perairan Timur Surabaya. Depik, 4(2): 79-86.

Radiarta, I. N. (2013). Hubungan Antara Distribusi Fitoplankton dengan Kualitas Perairan di Selat Alas Kabupaten Sumbawa, Nusa Tenggara Barat. Jurnal Bumi Lestari, 13(2): 234-243.
Radiarta, I. N., Erlania, \& Sugama, K. (2015). Analisis Spasial dan Temporal Komunitas Fitoplankton Sekitar Budidaya Laut Terintegrasi di Teluk Ekas, Nusa Tenggara Barat. Jurnal Riset Akuakultur, 10(2): 283-291.

Romimohtarto, K., \& S. Juwana (2007). Biologi Laut: Ilmu Pengetahuan tentang Biota Laut. Jakarta: Djambatan.

Sentosa, A. A., \& Dharmadi (2017). Hasil Tangkapan Dan Kelimpahan Relatif Beberapa Jenis Hiu yang Didaratkan Di Tanjung Luar, Lombok. Widyariset, 3(2): 131-142.

Siburian, R., L. Simatupang., \& M. Bukit (2017). Analisis Kualitas Perairan Laut Terhadap Aktivitas di Lingkungan Pelabuhan Waingapu-Alor Sumba Timur. Jurnal Pengabdian Kepada Masyarakat, 23(1): 225-232.

Soedibjo, B. S. (2007). Pengaruh Faktor Lingkungan Terhadap Distribusi Spasial Komunitas Zooplankton di Teluk Klabat, Perairan Bangka Belitung. Oseanologi dan Limnologi di Indonesia, 33: 27-63.

Sulistiowati, D., R. H. R. Tanjung, \& D. Lantang. (2016). Keragaman dan Kelimpahan Plankton Sebagai Bioindikator Kualitas Lingkungan di Perairan Pantai Jayapura. Jurnal Biologi Papua, 8(2): 79-96.

Usman, M. S., Kusen, J. D., \& Rimper, J. R. T. S. (2013). Struktur Komunitas Plankton di Perairan Pulau Bangka Kabupaten Minahasa Utara. Jurnal Pesisir Dan Laut Tropis, 2(1): 51-57.

Wahyudi, A., E. Lubis, \& A. B. (2017). Strategi Pencegahan Pencemaran Lingkungan Pelabuhan Perikanan: Kasus Pelabuhan Perikanan Nusantara Palabuhanratu. Albacore, 1(2): 139-152.

Wardhana (2006). Pelatihan Penyusun Analisis Mengenai Dampak Lingkungan: 
Audah, N. et al. (2021). Jurnal Biologi Tropis, 21 (2): 448 - 455

DOI: http://dx.doi.org/10.29303/jbt.v21i2.2699

MetodaPrakiraan Dampak dan

Pengelolaannya pada Komponen Biota

Akuatik. Jakarta: Universitas Indonesia.

Wehr J.D., \& R. G. Sheath (2003). Freshwater Algae of North America Ecology and Classification. Sydney Tokyo: Academic Press.

Wiyarsih, B., H. Endrawati., \& S. Sedjati. (2019). Komposisi dan Kelimpahan Fitoplankton di Laguna Segara Anakan,Cilacap. Buletin Oseanografi Marina, 1(8): 1-8.

Wulandari, D.Y., N. T. M. Pratiwi, \& E. M. Adiwilaga (2014). Distribusi Spasial Fitoplankton di Perairan Pesisir Tangerang. Jurnal Ilmu Pertanian Indonesia (JIPI), 19(3): 156-162.

Yuliana, E. M. Adiwilaga, E. Harris., \& N. T. M. Pratiwi (2012). Hubungan antara Kelimpahan Fitoplankton dengan Parameter Fisik-Kimiawi Perairan di Teluk Jakarta. Jurna Akuatika, 3(2): 169179. 